\title{
Pembangunan Synonym Set Kosa Kata Al-Quran dengan Pendekatan WordNet
}

\author{
Laras Gupitasari*1, Moch. Arif Bijaksana ${ }^{2}$, Arief Fatchul Huda ${ }^{3}$ \\ 1,2Universitas Telkom; Jl. Telekomunikasi No.01, Dayeuhkolot, Bandung, (022) 7565930 \\ ${ }^{3}$ UIN Sunan Gunung Djati; Jl. A.H. Nasution No.105, Cipadung, Bandung, (022) 7800525 \\ 1,2Program Studi Informatika, Bandung \\ ${ }^{3}$ Fakultas Sains dan Teknologi, Bandung \\ e-mail: *1larasgupitasari@ student.telkomuniversity.ac.id, \\ ${ }^{2}$ arifbijaksana@telkomuniversity.ac.id, ${ }^{3}$ afh@uinsgd.ac.id
}

\begin{abstract}
Abstrak
Penelitian mengenai Al-Quran di bidang computational linguistics sangat menarik dan bermanfaat apabila dipandang dari seberapa pentingnya Al-Quran bagi umat Islam karena merupakan kitab suci Agama Islam. Penelitian ini bertujuan untuk membangun synonym set AlQuran karena saat ini sumber daya untuk melakukan penelitian mengenai Al-Quran dapat dikatakan masih kurang. Dataset yang digunakan pada penelitian ini yaitu kata benda terjemahan Bahasa Inggris Al-Quran. Untuk menghasilkan synonym set, penelitian ini mengelompokkan kata menggunakan metode hierarchical clustering dan jarak antar kata dihitung menggunakan path similarity dari WordNet.Evaluasi pada penelitian ini menghasilkan nilai F-Measure sebesar 83\% yang merupakan kesesuaian hasil synonym set oleh sistem dan hasil synonym set oleh ahli.
\end{abstract}

Kata kunci-Al-Quran, Synonym Set, Tesaurus, WordNet, Clustering

\begin{abstract}
Research about Quran in the field of computational linguistics is very interesting anduseful if it viewed from how important Quran is for the Muslims because it is the holy book ofIslam. This is research aims to establish a synonym set of Quran because nowadaysresources to conduct research on Al-Quran can be said still not enough. The dataset used inthis research is the english translated noun from the Quran. To produce synonym sets, thisresearch groups word using a hierarchical clustering method and the distance between words ismeasured using path similarity from WordNet. The evaluation of this research results gained F-Measure value $83 \%$ which is the suitability of the results of the synonym set by system and synonym setresults by linguist.
\end{abstract}

Keywords - Quran, Synonym Set, Thesaurus, WordNet, Clustering

\section{PENDAHULUAN}

Saat ini telah banyak penelitian linguistik dan Natural Language Processing (NLP) yang memanfaatkan Princeton WordNet (PWN)[1] sebagai bahan penelitian seperti pada pembangunan WordNet untuk Bahasa Turki [2], Bahasa Arab [3], Bahasa China [4], pembangunan Synonym Set untuk Bahasa Indonesia [5], dan masih banyak penelitian lainnya. 
Penelitian ini memiliki tujuan untuk membangun synonym set atau synset Bahasa Arab pada Al-Quran dengan memanfaatkan lexical semantic similarity pada PWN. Pada penelitian sebelumnya mengenai pembangunan WordNet Bahasa Arab [3] telah berhasil membangun lexical databaseWordNet dengan fokus Bahasa Arab modern. Pada penelitian ini akan berfokus pada kosa kata dalam Al-Quran.

Al-Quran memiliki surah sebanyak 114 surah dan ayat berjumlah 6.236 ayat. Dari sekian banyak ayat yang ada, setiap ayat memiliki kaitan dengan sebagian ayat yang lainnya. Begitupun dengan kata dalam setiap ayat juga memiliki kaitan dengan sebagian kata yang lainnya, salah satu kaitannya yaitu kesamaan makna dari setiap kata. Bagi pembaca yang kurang memahami Bahasa Arab dan hanya membaca beberapa kata saja dalam Al-Quran, dapat menyebabkan kurangnya pemahaman mengenai arti sebenarnya dari setiap kata dalam AlQuran.

Setiap kata dalam Al-Quran dapat memiliki makna lebih dari satu, contohnya adalah

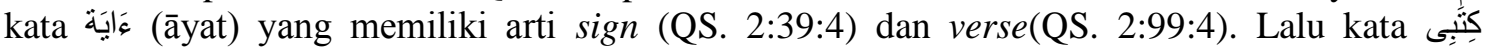
(kitābī) yang memiliki arti book (QS. 2:2:2), scripture (QS. 2:23:8), dan record (QS. 11:6:15). Selain kata yang memiliki makna lebih dari satu, sebagian kata juga memiliki arti yang sama atau dekat, contohnya adalah kata رَبّ (rab) yang memiliki arti Lord (QS. 1:2:3) dan إِّلَ (ilāh) yang memiliki arti God (QS. 2:133:17) dimana Lord dan God memiliki kedekatan makna yaitu Tuhan.

Sumber daya bahasa sangat penting untuk penelitian komputasi linguistik khususnya Natural Language Processing (NLP). Namun untuk korpus Bahasa Arab Al-Quran saat ini masih tergolong kurang walaupun beberapa tahun terakhir telah ada pengembangan korpuskorpus Bahasa Arab yang bebas akses. Korpus-korpus tersebut dapat dikatakan belum cukup mendorong para ahli bahasa untuk menerapkannya pada studi berbasis korpus mereka [6]. Oleh karena itu penelitian ini menjadi penting untuk membangun synonym set yang dapat digunakan sebagai prototype untuk membangun tesaurus Al-Quran.Synonym set yang terbentuk juga dapat digunakan untuk lebih memahami kosa kata - kosa kata pada Al-Quran.

Pendekatan utama dari penelitian ini adalah WordNet dan kamus monolingual yaitu tesaurus. Seperti yang kita tahu, WordNet merupakan lexical database Bahasa Inggris yang popular dan banyak digunakan oleh peneliti bidang komputasi linguistik dan NLP. Tesaurus juga merupakan kamus monolingual yang menyediakan hubungan sinonim antar kata dalam suatu bahasa [7] dan dapat diakses dengan bebas pada thesaurus.com atau www.lexico.com. Tersedia juga tesaurus dalam bentuk offline[7], [8]

\section{METODE PENELITIAN}

Data yang digunakan dalam penelitian ini adalah lema Al-Quran dan terjemahan Bahasa Inggris yang dapat diunduh di openburhan.net. Data tersebut berisikan total 77.794 baris data yang merupakan banyaknya kata yang ada dalam Al-Quran. Data tersebut akan diproses oleh sistem dengan memilah kata sehingga hanya kata benda saja yang akan digunakan. Proses dalam sistem dapat dilihat pada Gambar 1. 


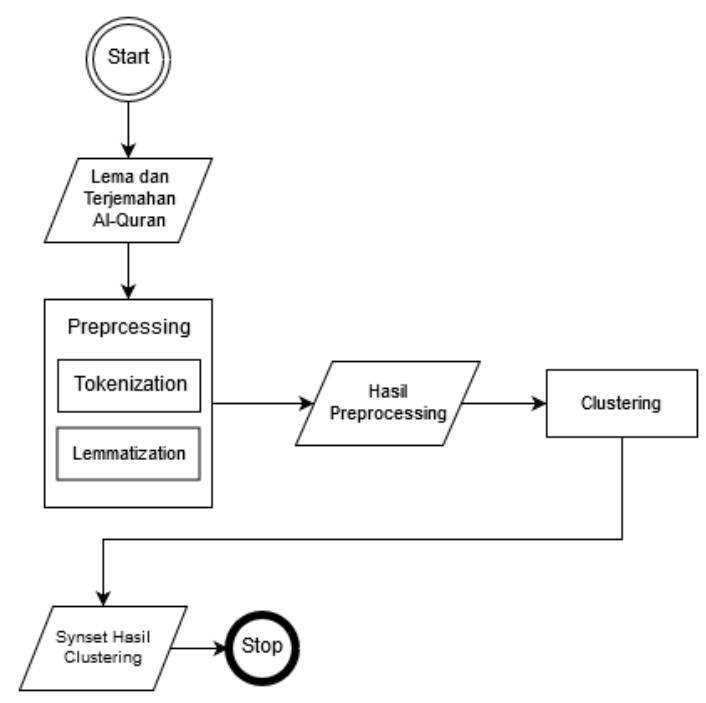

Gambar 1. Sistem Pembangunan Synonym Set

\subsection{Preprocessing}

Tujuan dari preprocessing ini adalah agar data yang digunakan siap untuk diproses oleh sistem. Karena data yang berkualitas tinggi akan menghasilkan hasil yang berkualitas tinggi juga dan dapat mengurangi biaya [9]. Data mentah dari openburhan.net berisikan daftar kata dasar Bahasa Arab atau dapat disebut lema, terjemahan setiap katanya dalam Bahasa Inggris dan juga letak setiap kata dalam Al-Quran. Karenatidak semua data mentah akan digunakan maka akan dilakukan proses preprocessing untuk memilah apa saja yang penting dan akan digunakan dalam penelitian ini. Proses preprocessing pada penelitian ini dilakukan dengan dua tahap yaitu tokenisasi dan lematisasi.

\subsubsection{Tokenisasi}

Terjemahan satu kata Bahasa Arab dalam Al-Quran tidak selalu memiliki satu arti saja, namun bergantung pada makna setiap ayatnya.Misalnya kata هُ هُ (hudan) yang memiliki arti 'for [the] guidance'. Karena penelitian ini berfokus pada kata benda saja maka untuk mendapatkan kata guidance perlu dilakukan proses tokenisasi untuk memisahkan token yang ada pada terjemahan sekaligus juga menghilangkan karakter-karakter yang tidak diperlukan. Tabel 1 berisikanbeberapa contoh proses tokenisasi.

Tabel 1. Proses Tokenisasi

\begin{tabular}{|l|l|}
\hline \multicolumn{1}{|c|}{ Sebelum proses tokenisasi } & Setelah proses tokenisasi \\
\hline $\begin{array}{l}\text { ['the lord', 'their lord', 'your lord', } \\
\text { 'his lord', 'your lord'] }\end{array}$ & ['lord'] \\
\hline $\begin{array}{l}\text { ['the earth', 'and the earth', 'the } \\
\text { earth', 'the earth', 'the earth'] }\end{array}$ & ['earth'] \\
\hline $\begin{array}{l}\text { ['to his people', 'o my people', 'for his } \\
\text { people', 'for people', 'a group'] }\end{array}$ & $\begin{array}{l}\text { ['people'], } \\
\text { ['group'] }\end{array}$ \\
\hline $\begin{array}{l}\text { ['our signs', 'my signs (for)', 'in (the) } \\
\text { signs', 'his signs'] }\end{array}$ & $\begin{array}{l}\text { ['signs'], } \\
\text { ['verses'], } \\
\text { ['sign'] }\end{array}$ \\
$\begin{array}{l}\text { ['with [the] messengers', 'a messenger', } \\
\text { 'and his messengers', 'a messenger'] }\end{array}$ & $\begin{array}{l}\text { ['messengers'], } \\
\text { ['messenger'] }\end{array}$ \\
\hline
\end{tabular}




\subsubsection{Lematisasi}

Setelah setiap kata pada terjemahan dipisahkan, selanjutnya adalah mengubah setiap kata menjadi bentuk kata dasarnya karena akan digunakan sebagai entri pada WordNet. Tabel 2berisikan hasil dari proses lematisasi dan entri yang akan digunakan pada sistem.

Tabel 2. Proses Lematisasi

\begin{tabular}{|c|c|}
\hline Hasil proses lematisasi & Entri pada sistem \\
\hline ['lord'] & ['j', 'lord'] \\
\hline ['earth'] & ['ضjji', 'earth'] \\
\hline ['people','group'] & 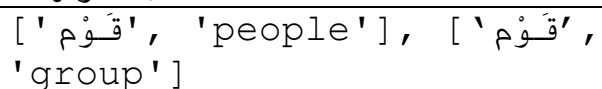 \\
\hline ['sign', 'verse'] & 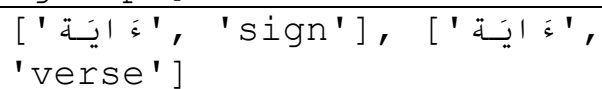 \\
\hline ['messenger'] & [' 'رَسُول \\
\hline
\end{tabular}

\subsubsection{Pengelompokan dengan Teknik Clustering}

Pada penelitian ini, teknik yang digunakanuntuk menggabungkan lema-lema yang memiliki kedekatan makna adalah menggunakan metode hierarchical clustering. Alasan memilih hierarchical clustering karena melihat dari tujuan penelitian ini yaitu untuk membangun synonym set yang tidak diketahui jumlahnya pada awal proses. Sehingga dengan menggunakan hierarchical clustering inisialisasi jumlah cluster tidak perlu dilakukan pada awal proses dan jumlah cluster tidak dapat diprediksi sebelum proses clustering selesai [10]. Fleksibilitas yang dimiliki oleh hierarchical clusteringjuga berguna pada biaya perhitungan yang lebih kecil [11].

Algoritma 1 adalah algoritma clustering yang digunakan pada penelitian ini.

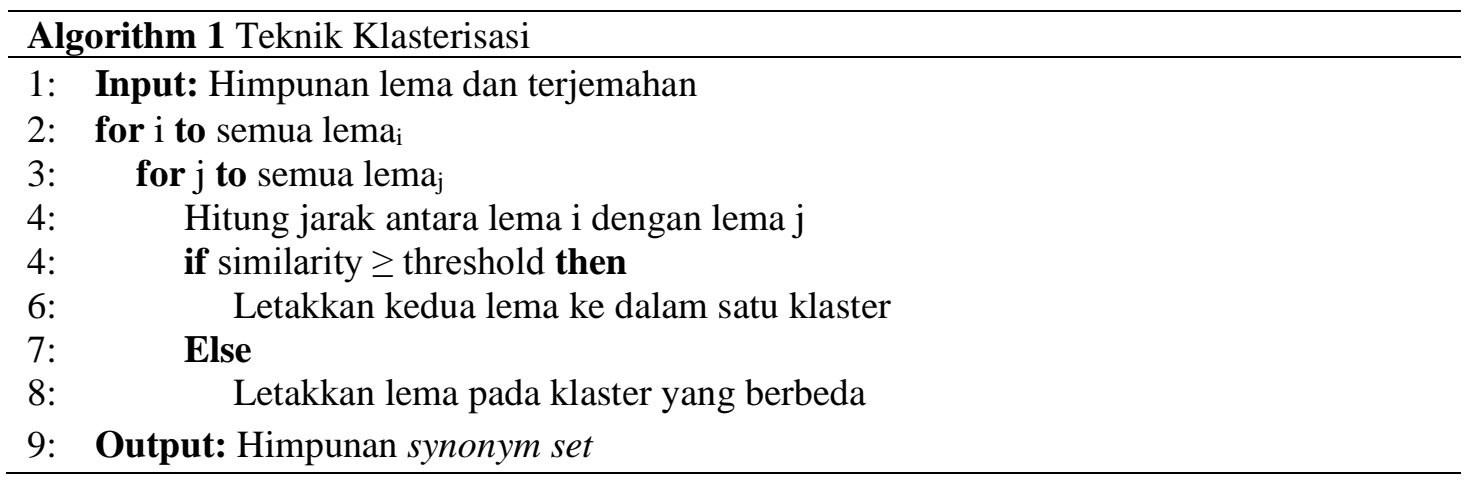

Perhitungan jarak dihitung menggunakan PATH similaritypada WordNet yaitu mengukur kedekatan antar kata dengan menghitung jumlah node pada jalur terpendek antar kata dan hubungan ' $i s-a$ ' antar kata pada WordNet [12]. Untuk mendapatkan jarak tersebut menggunakan Persamaan 1.

$$
\operatorname{PATH}(s 1, s 2)=\frac{1}{\text { path_length }(s 1, s 2)}
$$

$s 1$ merupakan kata pertama yang akan dibandingkan dengan kata kedua yaitus2. Nilai minimum yang akan dihasilkan adalah 0 dan nilai maksimumnya adalah 1.

Setelah perhitungan jarak antar kata, jarak tersebut dibandingkan dengan threshold sebesar 0.5. Nilai tersebut didapatkan atas hasil proses percobaan pada beberapa nilai dan dengan nilai 0.5 dapat menghasilkan synset yang cukup baik. Jika similarity sama dengan atau lebih besar dari threshold artinya antar kata memiliki kedekatan yang cukup besar dan jika similaritylebih kecil dari threshold artinya kedekatan antar kata adalah kecil. 
Lema-lema yang memiliki kedekatan besar akan digabungkan menjadi satu cluster atau himpunan kata yang memiliki kedekatan makna. Sehingga lema yang sama dapat berada lebih dari satu himpunan. Dan dalam satu himpunan dapat berisikan lebih dari satu lema yang memiliki kedekatan makna atau dapat disebut sinonim.

\section{HASIL DAN PEMBAHASAN}

Total lema kata benda yang digunakan pada penelitian ini adalah sebanyak 5.615 kata benda yang unik dalam Al-Quran. Dari 5.615 kata tersebut terdapat 427 kata atau sama dengan $11 \%$ keseluruhan data tidak ditemukan dalam database WordNet. Diantaranya kata sulaiman, firaun, safa, marwah dan lainnya yang merupakan kata dalam bahasa islami dan hanya ada pada Al-Quran. Tidak adanya kata-kata tersebut dalam database WordNet adalah karena WordNet merupakan lexical database gabungan dari kamus dan tesaurus Bahasa Inggris [13], sehingga untuk kata-kata tersebut bukan merupakan kata yang ada dalam kamus maupun tesaurus Bahasa Inggris.Kata lain yang juga tidak ada pada WordNet adalah kata I, my, they, him, dan lainnya karena merupakan kata dalam closed-class words pada WordNet terminologi [14].

Hasil synset oleh sistem dapat dilihat pada Tabel 3.

Tabel 3. Jumlah Hasil Synset yang Terbentuk

\begin{tabular}{|c|c|c|}
\hline $\begin{array}{c}\text { Synset berisi } \\
\text { single member }\end{array}$ & $\begin{array}{c}\text { Synset berisi multiple } \\
\text { member }\end{array}$ & Total \\
\hline 12 & 4552 & 4564 \\
\hline
\end{tabular}

Dari keseluruhan dataset sistem menghasilkan total synset sebanyak 4.564 dengan 12 synset berisikan satu lema saja dan 4.552 synset berisikan lebih dari satu lema. Beberapa contoh hasil synset beserta terjemahannya dapat dilihat pada pada Tabel 4.

Tabel 4. Beberapa Hasil Synonym Set Beserta Terjemahannya

\begin{tabular}{|c|c|}
\hline Entri & Synonym Set \\
\hline أَسْن & 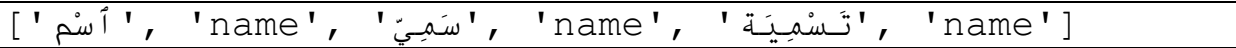 \\
\hline أَلله & 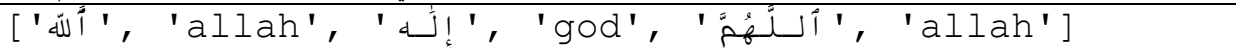 \\
\hline \multirow{2}{*}{ حَنْـد } & 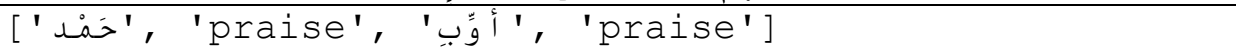 \\
\hline & 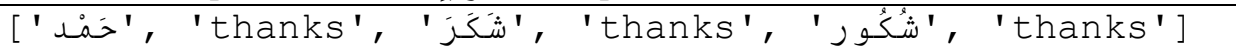 \\
\hline رَبّ & 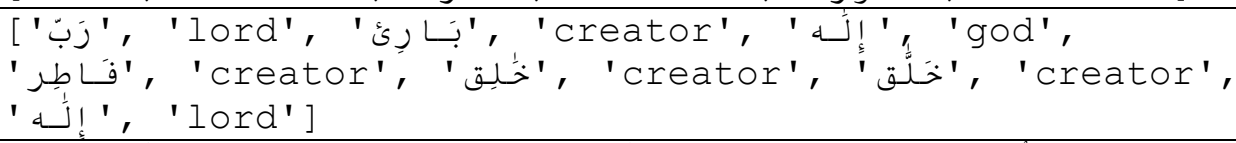 \\
\hline عُـلَمِيـنـن & 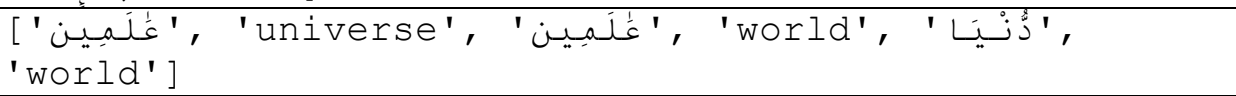 \\
\hline مـــــك & 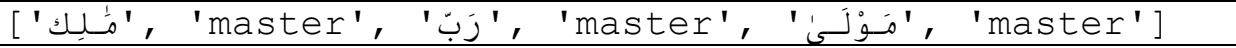 \\
\hline
\end{tabular}

Untuk mengetahui akurasi hasil synonym set yang terbentuk perlu dilakukan evaluasi. Pada penelitian ini metode yang digunakan untuk evaluasi adalah metode F-Measure karena FMeasure dapat digunakan untuk mengukur akurasi metode clustering[15] dengan melibatkan dua factor yaitu recall dan precision. Selain itu, proses evaluasi ini juga melibatkan ahli bahasa yaitu seseorang yang ahli dalam pemahaman Al-Quran untuk membuat gold standard yaitu synset yang benar menurut ahli. Persamaan 2 merupakan persamaan untuk menghitung recall dan Persamaan 3 adalah persamaan untuk menghitung precision. 


$$
\begin{aligned}
& \text { Recall }=\frac{N_{i j}}{N_{i}} \\
& \text { Precision }=\frac{N_{i j}}{N_{j}}
\end{aligned}
$$

Recall merupakan seberapa banyak elemen benar dalam synset yang terpilih, sedangkan precision adalah seberapa banyak elemen dalam synset terpilih merupakan elemenyang benar. $N_{i}$ adalah jumlah elemen pada synset oleh sistem dan $N_{j}$ adalah jumlah elemen padagold standard. Sedangkan $N_{i j}$ merupakan jumlah elemen synset oleh sistem yang ada pada gold standard. Kemudian persamaan untuk menghitung F-Measure terdapat pada Persamaan 4 dengan simbol $F$.

$$
F=\frac{2 * \text { Recall } * \text { Precision }}{\text { Recall }+ \text { Precision }}
$$

Tabel 5 berisikan hasil perbandingan synset oleh sistem dan synset oleh ahli atau gold

\begin{tabular}{|c|c|c|}
\hline $\begin{array}{l}\text { Entri } \\
\text { Kata }\end{array}$ & Synset oleh Sistem & $\begin{array}{l}\text { Synset oleh Ahli } \\
\text { (gold standard) }\end{array}$ \\
\hline 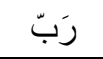 & [ خَلَّق , خُلِق , فَاطِر , إلَّه , بَارِئ , رَبّ ] & [ خَلَّق , خُلِق , فَاطِر , إلَّه , بَارِئ, رَبّ ] \\
\hline عَذَاب & 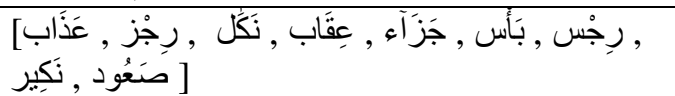 & [ بَأس , جَزَاءه, عِقَاب , نَكل , رِجْز , عَذَاب ] \\
\hline 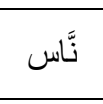 & 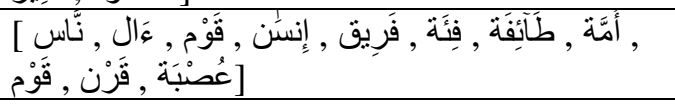 & 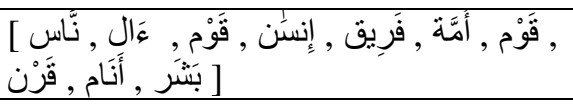 \\
\hline حَذَر & 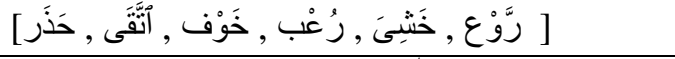 & ] ر رَّْع , خَثِتََ , رُعْب , خَوْف , حَذَر] \\
\hline ظَآلمِ & 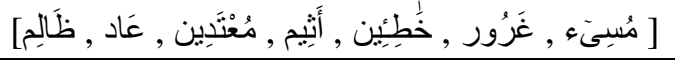 & 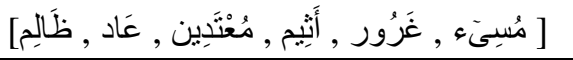 \\
\hline وَالِالد & 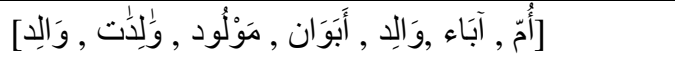 & 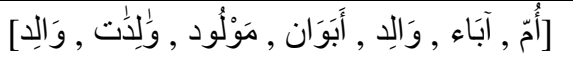 \\
\hline شَيَطْنُ & 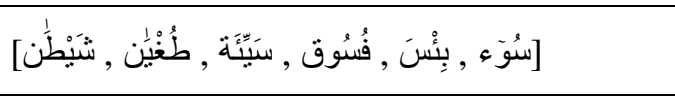 & 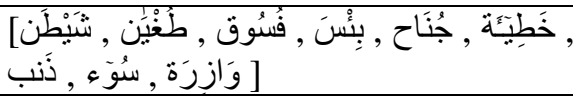 \\
\hline
\end{tabular}
standardmenggunakan 7 data uji.

Tabel 5.Perbandingan Synset

Menggunakan F-Measure sebagai metode evaluasi sistem mendapatkan nilai recall sebesar $81 \%$, nilai precision sebesar $86 \%$, dan F-measure sebesar $83 \%$. Faktor yang mempengaruhi nilai recall dan precision adalah karena terdapat selisih antara jumlah synset oleh sistem dan jumlah synset oleh gold standard sehingga mempengaruhi ketepatan elemen yang relevan.

\section{KESIMPULAN}

Pada penelitian ini hasil penggabungan kata menggunakan metodehierarchical clusteringdan pendekatan WordNet menghasilkan synonym set kosa kata Al-Quran sebanyak 4.564. Hasil synonym set dari penelitian ini dapat digunakan sebagai prototype untuk pembuatan korpus Al-Quran guna menambah sumber daya penelitian Al-Quran dan juga dapat digunakan oleh umat Islam untuk mempelajari kitabnya dengan lebih baik lagi. 


\section{SARAN}

Untuk penelitian selanjutnya diharapkan dapat menggunakan kelas kata yang lebih banyak dan tidak hanya kata benda saja. Pengukuran kedekatan antar kata menggunakan WordNet tidak dapat menangani kata yang tidak ada dalam kamus dan tesaurus Bahasa Inggris hal tersebut dapat mengurangi elemen dari synonym set. Sehingga, untuk menentukan jarak antar kata dan pengelompokan kata, metode lain layak dicoba demi meningkatkan akurasi dari pembangunan synonym set kosa kata Al-Quran.

\section{DAFTAR PUSTAKA}

[1] G. A. Miller, R. Beckwith, C. Fellbaum, D. Gross, and K. J. Miller 1990, "Introduction to WordNet: An on-line Lexical Database," Int. J. Lexicogr.

[2] O. Bilgin, Ö. Çetinoğlu, O. Cetinoglu, and K. Oflazer 2004, "Building a WordNet for Turkish,” Rom. J. Inf. Sci. Technol., Vol. 7, No. 1-2, pp. 163-172,

[3] S. Elkateb et al. 2006, "Building a WordNet for Arabic," in Proceedings of the 5th International Conference on Language Resources and Evaluation, LREC 2006, pp. 2934 .

[4] S. Wang and F. Bond 2013, "Building The Chinese Open Wordnet (COW): Starting from Core Synsets," in Proceedings of The 11th Workshop on Asian Language Resources, pp. 10-18.

[5] A. Saputra and Others 2010, "Building Synsets for Indonesian Wordnet with Monolingual Lexical Resources, " in 2010 International Conference on Asian Language Processing, pp. 297-300.

[6] A. Al-Thubaity, M. Khan, M. Al-Mazrua, and M. Al-Mousa 2013, "New Language Resources for Arabic: Corpus Containing More Than Two Million Words and A Corpus Processing Tool," in 2013 International Conference on Asian Language Processing, pp. $67-70$.

[7] T. Redaksi, "Tesaurus Bahasa Indonesia Pusat Bahasa, 2009, ” Pus. Bahasa, Dep. Pendidik. Nas., 2008.

[8] M. Waite, Oxford Thesaurus of English, Oxford University Press,

[9] S. A. N. Alexandropoulos, S. B. Kotsiantis, and M. N. Vrahatis 2019, Data Preprocessing in Predictive Data Mining, Vol. 34. Springer.

[10] K. N. PUTRI, 2019, “Clustering Ekstraksi Synonym Set Bahasa Indonesia Menggunakan

Agglomerative Hierarchical Clustering,", Skripsi, Program Studi Informatika, Universitas

Telkom, Bandung.

[11] Y. Rani and H. Rohil, "A Study of Hierarchical Clustering Algorithm," Int. J. Inf. 
Comput. Technol., p. 113, 2013.

[12] T. Pedersen, S. Patwardhan, and J. Michelizzi 2004,"WordNet:: Similarity: Measuring The Relatedness of Concepts, " in Demonstration Papers at HLT-NAACL 2004, , pp. 38 41.

[13] K. Samhith, S. A. Tilak, and G. Panda 2016, "Word Sense Disambiguation Using Wordnet Lexical Categories, " in 2016 International Conference on Signal Processing, Communication, Power and Embedded System (SCOPES), pp. 1664-1666.

[14] D. A. Wiranata, M. A. Bijaksana, and M. S. Mubarok 2018, "Quranic Concepts Similarity Based on Lexical Database," in 2018 6th International Conference on Information and Communication Technology (ICoICT), pp. 264-268.

[15] S. Chormunge and S. Jena, 2015, "Efficiency and Effectiveness of Clustering Algorithms for High Dimensional Data," Int. J. Comput. Appl. 